\title{
Cobertura vacinal para adolescentes, adultos e idosos em Marabá (PA), no período
}

\section{de 2015 a 2020}

\author{
Vaccination coverage for adolescents, adults and the elderly in Marabá (PA), from 2015 to 2020 \\ Cobertura de vacunación para adolescentes, adultos y ancianos en Marabá (PA), en el período de
}

2015 a 2020

Recebido: 09/05/2021 | Revisado: 13/05/2021 | Aceito: 13/05/2021 | Publicado: 10/06/2021

\author{
Ádria Rodrigues da Silva \\ ORCID: https://orcid.org/0000-0002-7233-0573 \\ Universidade do Estado do Pará, Brasil \\ E-mail: adriarodriguess@ hotmail.com \\ Daniela Soares Leite \\ ORCID: https://orcid.org/0000-0002-3412-1375 \\ Universidade do Estado do Pará, Brasil \\ E-mail: danielaleite@uol.com.br
}

\begin{abstract}
Resumo
Entre as ferramentas de prevenção no contexto da saúde pública, a vacinação merece destaque. Recentemente, entretanto, as imunizações passaram a enfrentar grandes obstáculos em território nacional, com o aumento dos índices de certas doenças infecciosas e a heterogeneidade da cobertura vacinal nas diferentes regiões brasileiras. Dessa forma, este estudo objetiva conhecer a cobertura das vacinas recomendadas pelo Ministério da Saúde para adolescentes, adultos e idosos, no município de Marabá, no período de 2015 à 2020. Trata-se de um estudo observacional, transversal e descritivo, onde foram entrevistados funcionários das salas de vacina das UBS (Unidade Básica de Saúde) da zona urbana de Marabá. Os dados foram coletados através de um questionário previamente elaborado pelos pesquisadores e por meio de informações advindas do Departamento de Informática do Sistema Único de Saúde (DATASUS). A pesquisa ofereceu riscos quanto à perda de sigilo de informações e constrangimento por parte dos entrevistados e a transmissão e adoecimento pelo novo coronavírus. Os resultados mostraram uma cobertura vacinal média de 57,49\% no período e lugar avaliado; evidenciou-se ausência de dados sobre a cobertura das vacinas contra influenza e HPV; as meninas se vacinaram mais que os meninos contra HPV, segundo doses aplicadas; a falta de conhecimento sobre a importância da vacinação foi o principal motivo para a não adesão deste público à vacinação, segundo os profissionais das salas de vacina. Estudos comparativos corroboraram as hipóteses e apoiaram estratégias de ampliação elencados por tais funcionários e destacaram baixas porcentagens de cobertura vacinal em vários locais brasileiros. É inegável a necessidade de intensificação das campanhas vacinais, a fim de proporcionar maior atração e conscientização do público alvo.
\end{abstract}

Palavras-chave: Imunização; Vacinação; Cobertura vacinal.

\begin{abstract}
Among the prevention tools in the context of public health, vaccination deserves to be highlighted. Recently, however, immunizations have come to face major obstacles in the national territory, with the increase in the rates of certain infectious diseases and the heterogeneity of vaccination coverage in different Brazilian regions. Thus, this study aims to know the coverage of vaccines recommended by the Ministry of Health for adolescents, adults and the elderly, in the municipality of Marabá, in the period from 2015 to 2020. It is an observational, cross-sectional and descriptive study, where they were interviewed vaccination rooms of the UBS (Basic Health Unit) in the urban area of Marabá. The data were collected through a questionnaire previously prepared by the researchers and through information from the Department of Informatics of the Unified Health System (DATASUS). The research offered risks regarding the loss of confidentiality of information and embarrassment on the part of the interviewees and the transmission and illness of the new coronavirus. The results showed an average vaccination coverage of $57.49 \%$ in the period and place evaluated; there was an absence of data on the coverage of vaccines against influenza and HPV; girls were vaccinated more than boys against HPV, according to doses applied; the lack of knowledge about the importance of vaccination was the main reason for this public's non-adherence to vaccination, according to professionals in the vaccination rooms. Comparative studies corroborated the hypotheses and supported expansion strategies listed by such employees and highlighted low percentages of vaccination coverage in several Brazilian locations. The need to intensify vaccination campaigns is undeniable, in order to provide greater attraction and awareness of the target audience.
\end{abstract}

Keywords: Immunization; Vaccination; Vaccination coverage. 


\begin{abstract}
Resumen
Entre las herramientas de prevención en el contexto de la salud pública, cabe destacar la vacunación. Recientemente, sin embargo, las inmunizaciones han enfrentado grandes obstáculos en el territorio nacional, con el aumento de las tasas de ciertas enfermedades infecciosas y la heterogeneidad de las coberturas de vacunación en las diferentes regiones brasileñas. Así, este estudio tiene como objetivo conocer la cobertura de vacunas recomendadas por el Ministerio de Salud para adolescentes, adultos y ancianos, en el municipio de Marabá, en el período de 2015 a 2020. Se trata de un estudio observacional, transversal y descriptivo, donde fueron entrevistados salas de vacunación de la UBS (Unidad Básica de Salud) en el área urbana de Marabá. Los datos fueron recolectados a través de un cuestionario previamente elaborado por los investigadores y a través de información del Departamento de Informática del Sistema Único de Salud (DATASUS). La investigación ofreció riesgos en cuanto a la pérdida de confidencialidad de la información y la vergüenza por parte de los entrevistados y la transmisión y enfermedad del nuevo coronavirus. Los resultados arrojaron una cobertura de vacunación promedio de $57,49 \%$ en el período y lugar evaluados; faltaron datos sobre la cobertura de las vacunas contra la influenza y el VPH; las niñas fueron vacunadas más que los niños contra el VPH, según las dosis aplicadas; El desconocimiento sobre la importancia de la vacunación fue el principal motivo de la falta de adhesión de este público a la vacunación, según los profesionales de las salas de vacunación. Los estudios comparativos corroboraron las hipótesis y apoyaron las estrategias de expansión enumeradas por dichos empleados y destacaron los bajos porcentajes de cobertura de vacunación en varias localidades brasileñas. Es innegable la necesidad de intensificar las campañas de vacunación, con el fin de brindar una mayor atracción y sensibilización del público objetivo.
\end{abstract}

Palabras clave: Inmunización; Vacunación; Cobertura de vacunación.

\title{
1. Introdução
}

Entre as ferramentas de prevenção no contexto da saúde pública, a vacinação merece destaque. No Brasil, as estratégias envolvidas têm alcançado altos índices de eficiência, bem como passaram a servir de parâmetro para iniciativas semelhantes em outros países (Porto \& Ponte, 2003).

O controle de doenças transmissíveis tem nos programas de imunizações e de vigilância epidemiológica dois componentes fundamentais (Moraes, 2007). Desde as primeiras vacinações, em 1804, o Brasil acumulou 216 anos de imunizações, sendo que nos últimos 40 anos, com a criação do PNI (Programa Nacional de Imunizações) em 1973, desenvolveu ações planejadas e sistematizadas. O PNI, criando antes mesmo do Sistema Único de Saúde (SUS), somente em 1988, foi determinante para o controle bem-sucedido das doenças imunopreveníveis no Brasil (Domingues et al, 2019). Estratégias diversas, campanhas, varreduras, rotina e bloqueios erradicaram a febre amarela urbana em 1942, a varíola em 1973 e a poliomielite em 1989, controlaram o sarampo, o tétano neonatal, as formas graves da tuberculose, a difteria, o tétano acidental, a coqueluche (Brasil, 2003).

No idos dos anos 90, a cobertura vacinal no Brasil era satisfatória, o que era um indício de aceitação da vacinação pela população, o que elevou o PNI a um patamar positivo. No entanto, é notável que o fortalecimento do movimento anti-vacina, contribuiu para a queda das coberturas vacinais o que favorece a reintrodução de doenças imunopreveníveis já em erradicadas, como ocorreu com o sarampo (Sato, 2018; Brasil, 2018). O sarampo estava controlado nas Américas e o Brasil tinha recebido o certificado de erradicação em 2016, porém o perdeu em 2018, pelo surgimento de surtos que ocorreram e perduram até os dias atuais (Medeiros, 2020; OPAS, 2021).

Recentemente, entretanto, as imunizações passaram a enfrentar grandes obstáculos em território nacional. Em 2017, a diminuição da busca pela vacinação levou o país às piores coberturas vacinais dos últimos 16 anos em crianças com até 12 meses. Este cenário permitiu que a importação do vírus do sarampo ocasionasse o ressurgimento de casos da doença em diferentes estados da federação, em especial no Amazonas e em Roraima, atingidos por um importante surto (SBIM, 2019). Segundo Arroyo et al (2020), o quantitativo de imunizações no país tende a variar entre os municípios brasileiros.

Segundo dados do Ministério da Saúde publicados em janeiro de 2019, os adolescentes, adultos e até mesmo os idosos foram vítimas da doença. O destaque vai para as pessoas com idade entre 15 e 29 anos, responsáveis por 46,2\% dos casos confirmados no Amazonas, estado que concentrou 95\% dos registros (SBIM, 2019). 
Atualmente, o PNI oferece acesso universal e gratuito para 44 imunobiológicos, incluindo 19 vacinas no calendário de rotina, para todas as faixas etárias em aproximadamente 34 mil salas de vacinação, e promove, todos os anos, campanhas de vacinação contra influenza (Ferreira et al., 2018). As Tabelas 1, 2 e 3 apresentam os atuais esquemas vacinais disponibilizados pelo PNI.

De modo recente, o programa elevou sua complexidade com a introdução de diversas vacinas. Esse rápido desenvolvimento traz novos desafios, como atingir e manter altas coberturas vacinais, mesmo em locais onde as doenças imunopreveníveis já estão controladas (Ferreira et al., 2018).

Tabela 1: Calendário vacinal da criança.

\begin{tabular}{|c|c|c|c|c|c|}
\hline VACINA & PROTEÇÃ̃ & COMPOSIÇÃO & $\begin{array}{c}\text { ESQUEMA } \\
\text { BÁSICO } \\
\end{array}$ & REFORÇO & IDADE \\
\hline BCG & $\begin{array}{l}\text { Formas graves } \\
\text { de tuberculose }\end{array}$ & Bactéria viva atenuada & Dose única & - & Ao nascer \\
\hline Hepatite B & Hepatite B & $\begin{array}{l}\text { Antígeno recombinante de } \\
\text { superfície do vírus } \\
\text { purificado }\end{array}$ & $\begin{array}{l}\text { Dose } \\
\text { nascer }\end{array}$ & - & Ao nascer \\
\hline $\begin{array}{l}\text { Poliomielite 1, 2, } 3 \\
\text { (VIP - inativada) }\end{array}$ & Poliomielite & $\begin{array}{l}\text { Vírus inativado tipos } 1,2 \mathrm{e} \\
3\end{array}$ & 3 doses & $\begin{array}{l}2 \\
\text { com a vacina } \\
\text { VOP }\end{array}$ & 2,4 e 6 meses \\
\hline $\begin{array}{l}\text { Poliomielite } 1 \text { e } 3 \\
\text { (VOP - atenuada) }\end{array}$ & Poliomielite & $\begin{array}{l}\text { Vírus vivo atenuado tipos } \\
1 \text { e } 3\end{array}$ & - & $\begin{array}{l}2 \text { doses de } \\
\text { reforço }\end{array}$ & $\begin{array}{l}15 \text { meses e } 4 \\
\text { anos }\end{array}$ \\
\hline $\begin{array}{l}\text { Rotavírus humano } \\
\text { G1P1 (VRH) }\end{array}$ & $\begin{array}{l}\text { Diarreia por } \\
\text { Rotavírus }\end{array}$ & Vírus vivo atenuado & 2 doses & - & 2 e 4 meses \\
\hline $\begin{array}{l}\text { DTP }+ \text { Hib }+ \text { HB } \\
\text { (Penta) }\end{array}$ & $\begin{array}{l}\text { Difteria, Tétano, } \\
\text { Coqueluche, } \\
\text { Haemophilus } \\
\text { influenzae B e } \\
\text { Hepatite B }\end{array}$ & $\begin{array}{l}\text { Toxoides diftérico e } \\
\text { tetânico purificados e } \\
\text { bactéria de coqueluche } \\
\text { inativada. } \\
\text { Oligossacarídeos } \\
\text { conjugados do Hib, } \\
\text { antígeno de superfície de } \\
\text { HB }\end{array}$ & 3 doses & $\begin{array}{lr}2 & \text { reforços } \\
\text { com a vacina } \\
\text { DTP }\end{array}$ & 2,4 e 6 meses \\
\hline $\begin{array}{l}\text { Pneumocócica } \\
\text { valente }\end{array}$ & $\begin{array}{l}\text { Pneumonias, } \\
\text { Meningites, } \\
\text { Otites, Sinusites } \\
\text { pelos sorotipos } \\
\text { que compõem a } \\
\text { vacina }\end{array}$ & $\begin{array}{l}\text { Polissacarídeo capsular de } \\
10 \text { sorotipos pneumococos }\end{array}$ & 2 doses & Reforço & $\begin{array}{l}2 \text { e } 4 \text { meses } \\
\text { Reforço: } \\
\text { meses }\end{array}$ \\
\hline $\begin{array}{l}\text { Meningocócica } \quad \text { C } \\
\text { (conjugada) }\end{array}$ & $\begin{array}{l}\text { Meningite } \\
\text { meningocócica } \\
\text { tipo C }\end{array}$ & $\begin{array}{l}\text { Polissacarídeos capsulares } \\
\text { purificados da Neisseria } \\
\text { meningitis do sorogrupo C }\end{array}$ & 2 doses & Reforço & $\begin{array}{l}3 \text { e } 5 \text { meses } \\
\text { Reforço: } \\
\text { meses }\end{array}$ \\
\hline $\begin{array}{ll}\text { Febre } & \text { Amarela } \\
\text { (atenuada) } & \\
\end{array}$ & Febre amarela & Vírus vivo atenuado & 1 dose & Reforço & $\begin{array}{l}9 \text { meses } \\
\text { Reforço: } 4 \text { anos }\end{array}$ \\
\hline $\begin{array}{l}\text { Sarampo, Caxumba, } \\
\text { Rubéola } \\
\text { viral) }\end{array}$ & $\begin{array}{l}\text { Sarampo, } \\
\text { Caxumba, } \\
\text { Rubéola }\end{array}$ & Vírus vivo atenuado & $\begin{array}{l}2 \text { doses }\left(1^{\mathrm{a}}\right. \\
\text { dose com a } \\
\text { tríplice e } 2^{\mathrm{a}} \\
\text { com a tetra) }\end{array}$ & - & 12 meses \\
\hline $\begin{array}{l}\text { Sarampo, Caxumba, } \\
\text { Rubéola, } \\
\text { (Tetra viral) }\end{array}$ & $\begin{array}{l}\text { Sarampo, } \\
\text { Caxumba, } \\
\text { Rubéola, } \\
\text { Varicela }\end{array}$ & Vírus vivo atenuado & 1 dose & - & 15 meses \\
\hline Hepatite A & Hepatite A & $\begin{array}{l}\text { Antígeno do vírus da } \\
\text { hepatite } \mathrm{A} \text {, inativada }\end{array}$ & 1 dose & - & 15 meses \\
\hline $\begin{array}{l}\text { Difteria, Tétano, } \\
\text { Pertussis (DTP) }\end{array}$ & $\begin{array}{l}\text { Difteria, Tétano } \\
\text { e Coqueluche }\end{array}$ & $\begin{array}{l}\text { Toxoides diftérico e } \\
\text { tetânico purificados e } \\
\text { bactéria de coqueluche } \\
\text { inativada. }\end{array}$ & $\begin{array}{l}\text { Considerar } \\
\text { doses } \\
\text { anteriores } \\
\text { doses })\end{array}$ & 2 reforços & $\begin{array}{l}15 \text { meses e } 4 \\
\text { anos }\end{array}$ \\
\hline Difteria e Tétano (dT) & $\begin{array}{l}\text { Difteria } \\
\text { Tétano }\end{array}$ & $\begin{array}{l}\text { diftérico e } \\
\text { purificados, }\end{array}$ & $\begin{array}{l}\text { Considerar } \\
\text { doses } \\
\text { anteriores } \\
\text { com penta e } \\
\text { DTP (3 doses) }\end{array}$ & $\begin{array}{l}\text { A cada } 10 \\
\text { anos. Em caso } \\
\text { de ferimentos } \\
\text { graves, a cada } \\
5 \text { anos }\end{array}$ & $\begin{array}{l}\text { A partir dos } 7 \\
\text { anos }\end{array}$ \\
\hline
\end{tabular}




\begin{tabular}{|c|c|c|c|c|c|c|}
\hline $\begin{array}{l}\text { Papilomavírus } \\
\text { humano (HPV) }\end{array}$ & & $\begin{array}{l}\text { HPV 6, 11, 16, } \\
18 \\
\text { (recombinante) }\end{array}$ & $\begin{array}{lll}\text { Partícula da cápsula } & \text { do } \\
\text { vírus } & \text { antígeno } & \text { de } \\
\text { superfície } & & \\
& & \end{array}$ & 2 doses & - & $\begin{array}{l}9 \text { a } 14 \text { anos para } \\
\text { meninas; de } 11 \\
\text { a } 14 \text { anos para } \\
\text { meninos }\end{array}$ \\
\hline $\begin{array}{l}\text { Pneumocócica } \\
\text { valente }\end{array}$ & 23- & $\begin{array}{l}\text { Meningites } \\
\text { bacterianas, } \\
\text { Pneumonias, } \\
\text { Sinusites etc. }\end{array}$ & $\begin{array}{l}\text { Polissacarídeo capsular de } \\
23 \text { sorotipos pneumococos }\end{array}$ & 1 dose & $\begin{array}{lr}\quad \text { dose } & \text { a } \\
\text { depender } & \text { da } \\
\text { situação } & \\
\text { vacinal } & \\
\end{array}$ & $\begin{array}{l}\text { A partir dos } 5 \\
\text { anos para os } \\
\text { povos indígenas }\end{array}$ \\
\hline Varicela & & Varicela & Vírus vivo atenuado & 1 dose & - & 4 anos \\
\hline Influenza & & Influenza & $\begin{array}{ll}\text { Vírus } & \text { fracionado, } \\
\text { inativado } & \end{array}$ & $\begin{array}{l}1 \text { dose ou } 2 \\
\text { doses }\end{array}$ & Dose anual & 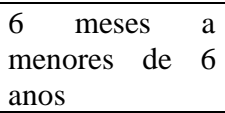 \\
\hline
\end{tabular}

Fonte: Ministério da Saúde (2020).

Tabela 2: Calendário vacinal do adolescente.

\begin{tabular}{|c|c|c|c|c|c|c|}
\hline VACINA & PROTEÇÃO & COMPOSIÇÃO & \multicolumn{2}{|c|}{$\begin{array}{c}\text { ESQUEMA } \\
\text { BÁSICO } \\
\end{array}$} & REFORÇO & IDADE \\
\hline Hepatite B & Hepatite B & $\begin{array}{l}\text { Antígeno recombinante de } \\
\text { superfície do vírus } \\
\text { purificado }\end{array}$ & $\begin{array}{l}\text { Iniciar } \\
\text { completar } \\
\text { doses }\end{array}$ & $\begin{array}{r}\text { ou } \\
3\end{array}$ & - & - \\
\hline $\begin{array}{l}\text { Difteria e Tétano } \\
\text { (dT) }\end{array}$ & $\begin{array}{l}\text { Difteria } \\
\text { Tétano }\end{array}$ & $\begin{array}{l}\text { Toxoides diftérico e } \\
\text { tetânico } \\
\text { inativada }\end{array}$ & $\begin{array}{l}\text { Iniciar } \\
\text { completar } \\
\text { doses }\end{array}$ & $\begin{array}{r}\text { ou } \\
3\end{array}$ & $\begin{array}{l}\text { A cada } 10 \\
\text { anos. Se } \\
\text { ferimentos } \\
\text { graves, a cada } \\
5 \text { anos }\end{array}$ & - \\
\hline $\begin{array}{l}\text { Sarampo, } \\
\text { Caxumba, } \\
\text { Rubéola (Tríplice) }\end{array}$ & $\begin{array}{l}\text { Sarampo, } \\
\text { Caxumba } \\
\text { Rubéola }\end{array}$ & Vírus vivo atenuado & $\begin{array}{l}\text { Iniciar } \\
\text { completar } \\
\text { doses }\end{array}$ & $\begin{array}{r}\text { ou } \\
2\end{array}$ & - & - \\
\hline $\begin{array}{l}\text { Papilomavírus } \\
\text { humano (HPV) }\end{array}$ & $\begin{array}{l}\text { HPV 6, 11, 16, } \\
18 \\
\text { (recombinante) }\end{array}$ & $\begin{array}{lll}\text { Partícula da cápsula } & \text { do } \\
\text { vírus antígeno } & \text { de } \\
\text { superfície } & & \end{array}$ & $\begin{array}{l}\text { Iniciar } \\
\text { completar } \\
\text { doses }\end{array}$ & $\begin{array}{r}\text { ou } \\
2\end{array}$ & - & $\begin{array}{l}9 \text { a } 14 \text { anos para } \\
\text { meninas; de } 11 \\
\text { a } 14 \text { anos para } \\
\text { meninos }\end{array}$ \\
\hline $\begin{array}{l}\text { Pneumocócica 23- } \\
\text { valente }\end{array}$ & $\begin{array}{l}\text { Meningites } \\
\text { bacterianas, } \\
\text { Pneumonias, } \\
\text { Sinusites etc. }\end{array}$ & $\begin{array}{l}\text { Polissacarídeo capsular de } \\
23 \text { sorotipos pneumococos }\end{array}$ & 1 dose & & $\begin{array}{lr}1 \quad \text { dose } & \text { a } \\
\text { depender } & \text { da } \\
\text { situação } & \\
\text { vacinal } & \\
\end{array}$ & $\begin{array}{l}\text { A partir dos } 5 \\
\text { anos para os } \\
\text { povos indígenas }\end{array}$ \\
\hline $\begin{array}{l}\text { Meningocócica } \mathrm{C} \\
\text { (conjugada) }\end{array}$ & $\begin{array}{l}\text { Meningite } \\
\text { meningocócica } \\
\text { tipo C }\end{array}$ & $\begin{array}{l}\text { Polissacarídeos capsulares } \\
\text { purificados da Neisseria } \\
\text { meningitis do sorogrupo C }\end{array}$ & 1 dose & & - & 11 e 12 anos \\
\hline Febre Amarela & Febre Amarela & Vírus vivo atenuado & $\begin{array}{l}\text { Reforço, } \\
\text { recebido } \\
\text { completar }\end{array}$ & & $\begin{array}{l}\text { a pessoa tenha } \\
\text { dose antes de } \\
\text { s }\end{array}$ & - \\
\hline
\end{tabular}

Fonte: Ministério da Saúde (2020). 
Tabela 3: Calendário vacinal do adulto e do idoso.

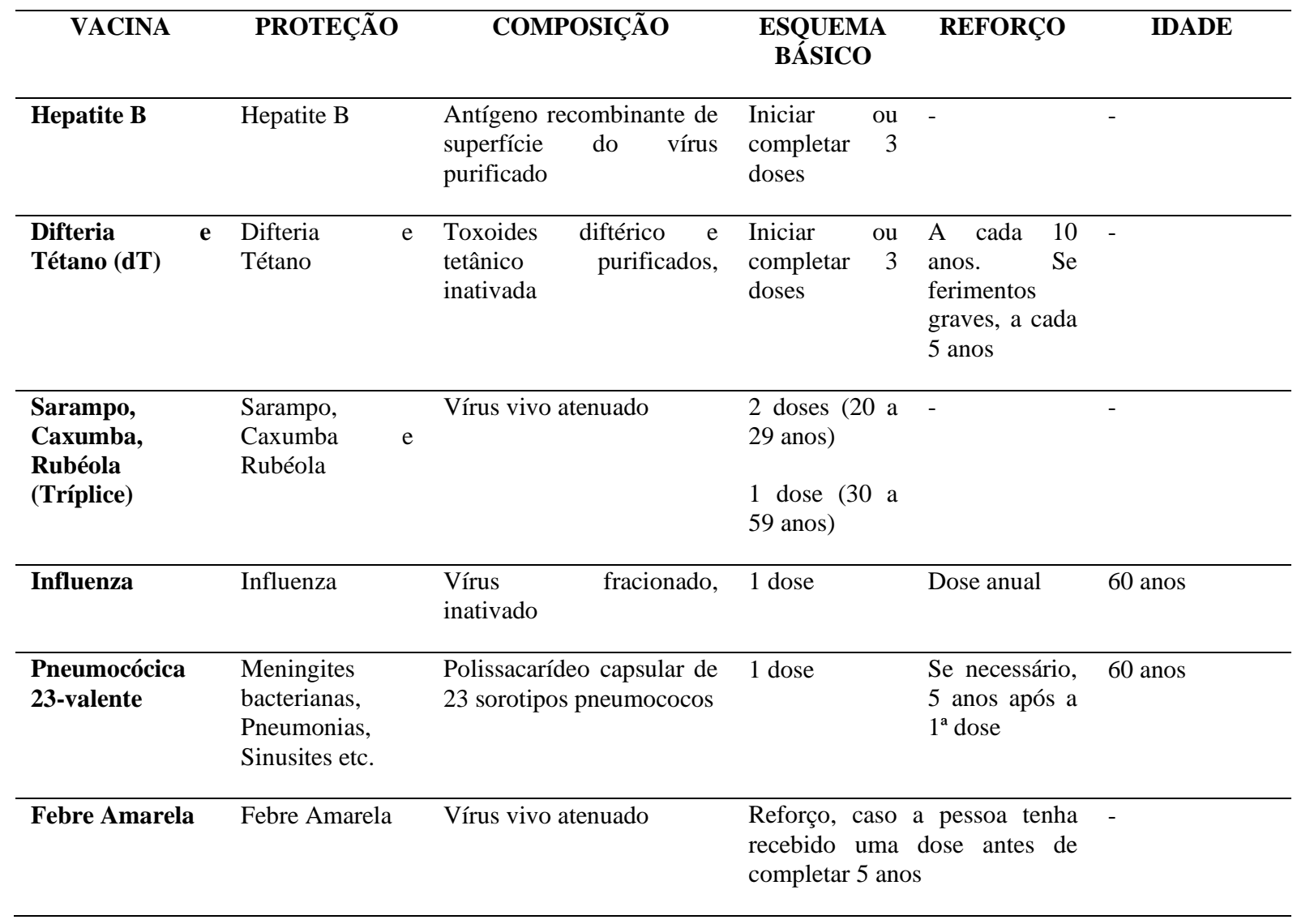

Fonte: Ministério da Saúde (2020).

A cobertura vacinal brasileira é estimada a partir dos dados registrados pelas unidades básicas de saúde, sendo susceptível a importante erro de registro, transcrição, estimativa de população alvo etc. A ocorrência de epidemias na vigência de estimativas de coberturas altas, bem como os inquéritos domiciliares realizados, tem demonstrado a imprecisão desses cálculos. A heterogeneidade de cobertura, nem sempre corretamente evidenciada, representa risco de introdução e manutenção da circulação de agentes infecciosos em certos estratos populacionais (Moraes, 2007).

Nesse contexto, conhecer a atual situação da cobertura vacinal do município de Marabá é o primeiro passo para o reconhecimento de tendências locais em comparação às demais localidades brasileiras, para assim identificar possíveis discrepâncias. Desta forma, uma nova estratégia de prevenção poderá ser desenvolvida.

Além disso, é importante ressaltar que o Brasil passa por um processo de envelhecimento acelerado. Segundo projeções do Instituto Brasileiro de Geografia e Estatística (IBGE), a população com 60 anos ou mais crescerá cerca de 50\% nos próximos dez anos. Em 2039, pela primeira vez na história, o número de indivíduos com mais de 65 anos superará o de pessoas com até 14 anos. E, em 2060, aproximadamente um a cada quatro brasileiros será idoso (SBIM, 2019).

Aliado a esta visão, levando-se em conta as altas taxas de infecção nas faixas etárias maiores durante surtos epidêmicos e a suscetibilidade dos idosos a infecções, sequelas e mortes por enfermidades imunopreveníveis, julga-se igualmente importante reconhecer a adesão desta população às estratégias de imunizações, bem como a opinião de profissionais da saúde acerca dos fatores que podem levar à má cobertura vacinal entre os adolescentes, adultos e idosos.

Assim, os objetivos desse trabalho foi conhecer a cobertura das vacinas recomendadas pelo Ministério da Saúde para adolescentes, adultos e idosos, no município de Marabá, no período de 2015 a 2020 e analisar a percepção dos funcionários da sala de vacina acerca dos desafios encontrados na campanha de vacinação. 


\section{Metodologia}

\section{Desenho do estudo}

Trata-se de um estudo ecológico descritivo, com abordagem quantitativa e qualitativa. O local de estudo foi o município de Marabá/PA. A cidade divide-se em cinco núcleos urbanos distintos: Marabá Pioneira ou Velha Marabá localizada as margens dos rios, Cidade Nova, onde se situa o aeroporto, Nova Marabá onde os bairros recebem o nome de folhas numeradas, São Felix I e II, situados depois da ponte sobre o rio Tocantins e Morada Nova, a 20 km de Marabá (Marabá, 2015).

O município de Marabá possui, hoje, 23 UBS (Unidade Básica de Saúde), dentre as quais 13 localizam-se na Zona Urbana e 10 na Zona Rural. Também conta com a participação de 23 ESF (Estratégia Saúde da Família) aprovadas pela Comissão Intergestora Regional (Marabá, 2016).

\section{Sujeitos da pesquisa}

Foram incluídos na pesquisa 20 funcionários responsáveis por cada sala de vacina das 13 UBS localizadas na zona urbana de Marabá; cada UBS apresenta uma sala de vacina, onde encontra-se de um a dois funcionários.

Foram excluídos do estudo aqueles que possuíam menos de 18 anos de idade ou que trabalham na zona rural, devido à dificuldade de locomoção dos pesquisadores até estas áreas, assim como os profissionais das UBS que não possuem ESF ou que não oferecem o serviço de vacinação.

\section{Coleta de dados}

Os dados foram coletados em abril de 2021, através de um questionário previamente elaborado pelos pesquisadores e por meio de informações advindas do Departamento de Informática do SUS (DATASUS), cujos dados são provenientes do Sistema de Informação do Programa Nacional de Imunização (SIPNI), o qual não é aberto ao público.

O formulário apresenta questionamentos acerca do serviço de vacinação da UBS em que o entrevistado trabalha, além da opinião do funcionário sobre a eficácia das campanhas municipais de imunizações e sobre os principais motivos de má adesão de adolescentes, adultos e idosos à vacinação.

Além disso, a cobertura vacinal por faixa etária foi avaliada após a computação dos dados coletados pelo DATASUS. O Programa Nacional de Imunizações, pelo Sistema API (Avaliação do Programa de Imunizações), tem como objetivo acompanhar sistematicamente o quantitativo populacional vacinado por faixa etária, além de controlar os índices de cobertura e taxas de abandono nos âmbitos Federal, Estadual e Municipal (Brasil, 2001).

Os questionários foram aplicados nas 13 UBS (ao funcionário responsável pelo serviço de vacinação) que possuem ESF no município de Marabá. Entre elas: Posto de Saúde Hiroshi Matsuda, Posto de Saúde Demósthenes Ayres Azevedo, Posto de Saúde da Liberdade, Centro de Saúde Laranjeiras, Centro de Saúde Enfermeira Zezinha, Centro de Saúde Pedro Cavalcante, Centro de Saúde Jaime Pinto, Posto de Saúde Maria Bico Doce, Unidade de Saúde João Batista Bezerra, Centro de Referência Integrada à Saúde da Mulher (CRISMU), Unidade Básica de Saúde Edivan Xavier, Centro de Saúde Amadeu Vivacqua e Centro de Saúde Mariana Moraes.

Foram realizadas visitas às unidades de saúde no horário de expediente, a fim de distribuir os questionários entre os profissionais alvos. A entrega do questionário era precedida da discussão e assinatura de um Termo de Consentimento Livre e Esclarecido (TCLE) para os profissionais que aceitassem participar da pesquisa, assegurando, dessa forma, o anonimato das pessoas que respondessem ao questionário, para que não houvesse informações que as identificassem. 


\section{Riscos e benefícios}

O presente estudo ofereceu riscos quanto à perda de sigilo de informações. Quanto a isso, os pesquisadores assinaram um termo de responsabilidade pelos dados coletados, garantindo a não divulgação até o término da pesquisa. Da mesma maneira, os funcionários entrevistados poderiam ser identificados, sob risco de se comprometer pelas respostas aplicadas no questionário. Para evitar tal ímpeto, os formulários não exigiram nome, assim como em nenhum momento da entrevista, o funcionário será obrigado a dizê-lo.

Ademais, os profissionais poderiam não se sentir à vontade para responder ao questionário, já que este aborda assuntos acerca da eficácia do trabalho público e, desta forma, pode gerar um sentimento de insegurança ou ameaça ao cargo trabalhista caso as respostas que revelem pontos negativos do serviço sejam divulgadas. Nesse caso, o funcionário pôde recusar-se a participar da pesquisa, sem ser cobrado alguma justificativa. Do mesmo modo, foi esclarecido que a origem de cada resposta não será divulgada em hipótese alguma.

Além disso, devido à pandemia do Covid-19, a entrevista presencial ofereceu risco de contágio para ambas as partes: entrevistado e entrevistador. Todavia, normas de biossegurança foram utilizadas, incluindo uso de álcool em gel antes e depois da entrevista e máscara facial. O uso de jaleco foi dispensado, já que não houve contato com os imunobiológicos ou quaisquer secreções biológicas, tratando-se apenas da troca de papel e caneta.

Por outro lado, o estudo contribui ao reconhecimento da cobertura vacinal para adolescentes, adultos e idosos no município de Marabá, assim como das possíveis causas de má adesão deste público às imunizações. Assim, novas estratégias poderão ser melhor direcionadas a fim de atrair este grupo populacional.

Os resultados ainda podem ajudar na compreensão epidemiológica dos novos aumentos de incidência de patologias infecciosas na região, como o sarampo, que anteriormente haviam sido erradicadas. Este monitoramento também é importante para estabelecer o risco de doença na população, particularmente para as enfermidades em que a idade está relacionada à gravidade ou a maiores complicações.

\section{Análise de dados}

Após a coleta dos dados, foi construída uma planilha eletrônica e os dados coletados foram agrupados, organizados e armazenados em ordem numérica, com o auxílio do Microsoft Excel 2013. A cobertura vacinal do município de Marabá foi representada em porcentagem, para cada vacina recomendada pelo Ministério da Saúde para adolescentes, adultos e idosos. Primeiramente, esse valor foi confrontado às metas desenvolvidas pelas autoridades federais, em seguida, foi comparado aos índices de outros municípios e regiões. Ademais, os motivos de má adesão do público alvo às imunizações dispostos nos questionários foram representados em frequência relativa e absoluta. Os dados sobre os serviços de vacinação nas UBS foram comparados a fim de avaliar se há padronização deste serviço no município. Por fim, os resultados foram apresentados por meio de gráficos e tabelas construídos através do Microsoft Word e Excel 2013, com suas respectivas legendas.

\section{Aspectos éticos}

O estudo obedeceu à Resolução no 466/2012 do Conselho Nacional de Saúde (CNS), que regulamenta a pesquisa envolvendo seres humanos, e foi conduzido após a submissão e aprovação pelo Comitê de Ética em Pesquisa envolvendo seres humanos CEP/Campus VIII/CCBS/UEPA, por meio do parecer número 4.613.307 e CAAE 42694720.9.0000.8607. A instituição não obteve nenhum tipo de ônus com a pesquisa, ficando estes sob a responsabilidade das pesquisadoras. 


\section{Resultados}

Em relação à cobertura vacinal de Marabá, no período de 2015 a 2020, o primeiro ponto a destacar é a ausência de dados, no site do DATASUS, sobre a cobertura vacinal de algumas vacinas, como influenza e HPV. Por conseguinte, observase que os únicos imunobiológicos que foram aplicados, atingindo a meta de 95\%, foram: BCG em 2019 e 2020, hepatite B (até 30 dias de vida) em 2019 e 2020, rotavírus em 2019, meningocócica, pneumocócica, poliomielite e tríplice viral em 2019. O restante das vacinas, nos anos expostos, não alcançou a meta desejada, conforme a Tabela 4. Ressalta-se ainda, que tal objetivo não foi atingido em nenhum ano considerando-se a cobertura total, a qual foi maior em 2019 (80,88\%) e menor em 2016 (40,67\%), com uma média de 57,49\% no período estudado.

Tabela 4: Cobertura vacinal de Marabá, de 2015 a 2020.

\begin{tabular}{|c|c|c|c|c|c|c|}
\hline Anos/Vacinas & 2015 & 2016 & 2017 & 2018 & 2019 & 2020 \\
\hline BCG & $73,87 \%$ & $80,56 \%$ & $75,20 \%$ & $81,53 \%$ & $107,3 \%$ & $123,3 \%$ \\
\hline Hepatite B (até 30 dias) & $74,23 \%$ & $45,46 \%$ & $70,20 \%$ & $73,22 \%$ & $102,85 \%$ & $120,17 \%$ \\
\hline Rotavírus & $65,47 \%$ & $65,27 \%$ & $52,91 \%$ & $68,46 \%$ & $99,69 \%$ & $75,02 \%$ \\
\hline Meningocócica & $71,86 \%$ & $64,63 \%$ & $57,16 \%$ & $44,26 \%$ & $103,9 \%$ & $71,75 \%$ \\
\hline Hepatite B & $67,08 \%$ & $72,13 \%$ & $47,74 \%$ & $47,29 \%$ & $71,28 \%$ & $58,19 \%$ \\
\hline Pentavalente & $66,08 \%$ & $63,96 \%$ & $47,74 \%$ & $47,29 \%$ & $71,28 \%$ & $58,19 \%$ \\
\hline Pneumocócica & $57,03 \%$ & $63,42 \%$ & $66,46 \%$ & $78 \%$ & $110,43 \%$ & $81,19 \%$ \\
\hline Poliomielite & $63,34 \%$ & $62,85 \%$ & $54,80 \%$ & $63,15 \%$ & $97,27 \%$ & $66,08 \%$ \\
\hline Febre amarela & $44,5 \%$ & $53,69 \%$ & $42,34 \%$ & $59,63 \%$ & $79,72 \%$ & $56,05 \%$ \\
\hline Hepatite A & $61,68 \%$ & $47,89 \%$ & $54,29 \%$ & $61,91 \%$ & $93,12 \%$ & $60,77 \%$ \\
\hline Pneumocócica $\left(1^{\circ}\right.$ reforço $)$ & $56,18 \%$ & $58,01 \%$ & $51,25 \%$ & $55,7 \%$ & $93,43 \%$ & $70,15 \%$ \\
\hline Meningocócica $\left(1^{\circ}\right.$ reforço) & $54,11 \%$ & $65,68 \%$ & $53,65 \%$ & $38,49 \%$ & $90,2 \%$ & $67,82 \%$ \\
\hline Poliomielite $\left(1^{\circ}\right.$ reforço $)$ & $44,22 \%$ & $34,59 \%$ & $42,18 \%$ & $47,80 \%$ & $76,68 \%$ & $57,35 \%$ \\
\hline Tríplice viral D1 & $64,5 \%$ & $68,39 \%$ & $57,29 \%$ & $71,3 \%$ & $108,08 \%$ & $65,6 \%$ \\
\hline Tríplice viral D2 & $38,17 \%$ & $49,36 \%$ & $42,41 \%$ & $59 \%$ & $85,24 \%$ & $59,01 \%$ \\
\hline Tetra viral & $34,77 \%$ & $49,40 \%$ & $38,85 \%$ & $49,21 \%$ & $59,42 \%$ & $35,98 \%$ \\
\hline DTP & $66,88 \%$ & $63,96 \%$ & $42,58 \%$ & $44,37 \%$ & $47,59 \%$ & $43,24 \%$ \\
\hline DTP $\left(1^{\circ}\right.$ reforço $)$ & $54,73 \%$ & $43,53 \%$ & $50,21 \%$ & $47,5 \%$ & $51,24 \%$ & $50,71 \%$ \\
\hline $\begin{array}{l}\text { DT adulto e tríplice acelular } \\
\text { gestante }\end{array}$ & $2,07 \%$ & $4,11 \%$ & $7,08 \%$ & $32,86 \%$ & $47,58 \%$ & $31,73 \%$ \\
\hline dTpa gestante & $2,20 \%$ & $4,27 \%$ & $9,52 \%$ & $49,04 \%$ & $64 \%$ & $39,61 \%$ \\
\hline Tetravalente & $71,84 \%$ & $11,39 \%$ & - & - & - & - \\
\hline Ignorado & 183,64 & 21,28 & - & - & - & - \\
\hline Total & $60,22 \%$ & $40,67 \%$ & $46,25 \%$ & $53,97 \%$ & $80,88 \%$ & $62,95 \%$ \\
\hline
\end{tabular}

Fonte: Autores.

Quanto às vacinas destinadas à adolescentes, adultos e idosos, pela ausência de dados completos sobre cobertura vacinal, optou-se por coletar o número de doses aplicadas. Utilizou-se o conceito de adolescente definido pela Organização Mundial da Saúde (OMS), que o circunscreve à segunda década de vida (de 10 a 19 anos) (Brasil, 2007). Entretanto, as doses dos imunobiológicos não estão agrupados em faixas etárias iguais e notou-se ausência de dados de influenza (2016 a 2018), pneumocócica 23 (2015 a 2018) e meningocócica C (2015 e 2016), conforme demonstra a Tabela 5. Nesse sentido, destaca-se a subnotificação de doses aplicadas de influenza e pneumocócica 23. Ademais, 2015 e 2016 foram os anos em que foram aplicadas menos vacinas, enquanto em 2019 mais doses foram registradas. 
Tabela 5: Imunobiológicos indicados a adolescentes, adultos e idosos - número de doses aplicadas.

\begin{tabular}{lccccccc}
\hline Vacinas & Faixa etária & $\mathbf{2 0 1 5}$ & $\mathbf{2 0 1 6}$ & $\mathbf{2 0 1 7}$ & $\mathbf{2 0 1 8}$ & $\mathbf{2 0 1 9}$ & $\mathbf{2 0 2 0}$ \\
\hline Hepatite B & $\geq 15$ anos & 4.118 & 2.016 & 6.701 & 6.161 & 10.584 & 8.656 \\
\hline Tríplice viral & $\geq 15$ anos & 177 & 222 & 285 & 517 & 11.880 & 24.196 \\
\hline Influenza & $\geq 30$ anos & 7 & - & - & - & 370 & 168 \\
\hline DT & $\geq 15$ anos & 9.182 & 5.000 & 10.970 & 8.509 & 13.061 & 10.388 \\
\hline Febre amarela & $\geq 10$ anos & 2.260 & 4.371 & 6.877 & 4.084 & 3.860 & 4.350 \\
\hline Pneumocócica 23 & $\geq 20$ anos & - & - & - & - & 8 & 16 \\
\hline Meningocócica C & $\geq 10$ anos & - & - & 759 & 624 & 2.200 & 1.431 \\
\hline
\end{tabular}

Fonte: Autores.

Em relação à vacina contra o Papilomavírus humano (HPV), observa-se que as mulheres receberam mais doses, em todos os anos estudados, quando comparadas aos homens, segundo o Gráfico 1. Ressalta-se também que a ausência de dados referentes às vacinas aplicadas nos homens, em 2015 e 2016, devem-se ao fato da disponibilização da imunização contra HPV, pelo Ministério da Saúde, a partir de 2017 para meninos.

Gráfico 1: Vacina contra o Papilomavírus humano (HPV) - doses aplicadas na faixa etária de 9 a 14 anos, conforme sexo e ano.

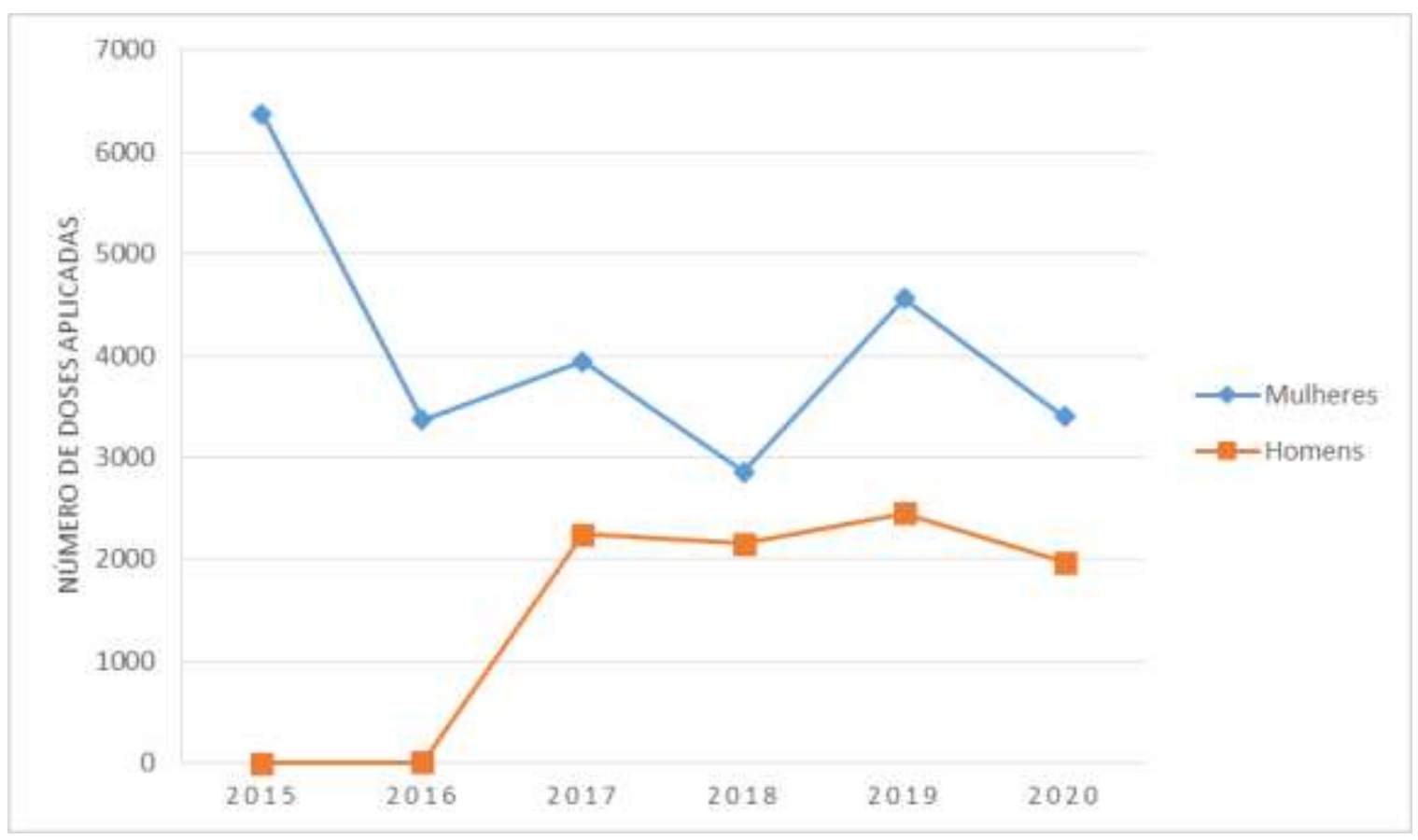

Fonte: Autores.

Em Marabá, os funcionários das salas de vacina das 13 UBS urbanas afirmaram que a unidade de saúde na qual trabalham disponibilizam vacinas para adolescentes, adultos e idosos (100\%), incluindo hepatite B, tríplice viral, Influenza, dT, HPV e febre amarela, conforme a Tabela 6. Apenas 3 (15\%) UBS possuem o imuno pneumocócica 23, porém os trabalhadores esclareceram que, quando necessária, esta vacina é solicitada ao CRIE (Centro de Referência para Imunobiológicos Especiais) por meio da apresentação, pelo paciente, de solicitação ou laudo médico. Ademais, a meningocócica C, apesar de essencial, estava em falta em duas UBS. 
Tabela 6: Opinião dos funcionários das salas de vacina de Marabá sobre a imunização no município.

\begin{tabular}{|c|c|c|c|}
\hline Questionamento & Respostas & $\begin{array}{c}\text { Frequência } \\
\text { absoluta }\end{array}$ & $\begin{array}{l}\text { Frequência } \\
\text { relativa }\end{array}$ \\
\hline \multirow{2}{*}{$\begin{array}{l}\text { A unidade de saúde em que você trabalha } \\
\text { disponibiliza vacinas para adolescentes, adultos e } \\
\text { idosos? }\end{array}$} & $\mathrm{Sim}$ & 20 & $100 \%$ \\
\hline & Não & 0 & 0 \\
\hline \multirow[t]{8}{*}{ Quais vacinas são disponibilizadas a este público? } & Hepatite B & 20 & $100 \%$ \\
\hline & Tríplice viral & 20 & $100 \%$ \\
\hline & Influenza & 20 & $100 \%$ \\
\hline & Difteria e Tétano (dT) & 20 & $100 \%$ \\
\hline & HPV & 20 & $100 \%$ \\
\hline & Febre amarela & 20 & $100 \%$ \\
\hline & Pneumocócica 23 & 3 & $15 \%$ \\
\hline & Meningocócica $\mathrm{C}$ & 18 & $90 \%$ \\
\hline \multirow{3}{*}{$\begin{array}{l}\text { Em quais turnos do dia a unidade de saúde em que } \\
\text { você trabalha disponibiliza essa vacinação? }\end{array}$} & Manhã & 20 & $100 \%$ \\
\hline & Tarde & 20 & $100 \%$ \\
\hline & Noite & 0 & 0 \\
\hline \multirow[t]{3}{*}{ Quais documentos são exigidos ao se vacinar? } & Cartão SUS & 20 & $100 \%$ \\
\hline & Carteira de vacinação & 17 & $85 \%$ \\
\hline & $\mathrm{CPF}$ & 5 & $25 \%$ \\
\hline \multirow{2}{*}{$\begin{array}{l}\text { Em sua opinião, a cobertura vacinal para } \\
\text { adolescentes, adultos e idosos, na sua unidade de } \\
\text { saúde, atinge o índice recomendado pelo Ministério } \\
\text { da Saúde? }\end{array}$} & Sim & 11 & $55 \%$ \\
\hline & Não & 9 & $45 \%$ \\
\hline \multirow{2}{*}{$\begin{array}{l}\text { Em sua opinião, as campanhas de imunização } \\
\text { promovidas pela Secretaria de Saúde de Marabá são } \\
\text { eficazes em conscientizar e atrair o público alvo } \\
\text { (neste caso, adolescentes, adultos e idosos)? }\end{array}$} & Sim & 12 & $60 \%$ \\
\hline & Não & 8 & $40 \%$ \\
\hline \multirow{12}{*}{$\begin{array}{l}\text { Dentre os possíveis motivos que levam os } \\
\text { adolescentes a não se vacinarem, quais destes você } \\
\text { considera mais importante? }\end{array}$} & $\begin{array}{l}\text { Falta de conhecimento acerca da } \\
\text { importância da vacinação }\end{array}$ & 14 & $70 \%$ \\
\hline & $\begin{array}{c}\text { Falta de conhecimento sobre } \\
\text { onde e quando se vacinar }\end{array}$ & 3 & $15 \%$ \\
\hline & $\begin{array}{c}\text { Falta de conhecimento sobre } \\
\text { quais vacinas recomendadas para } \\
\text { sua idade }\end{array}$ & 6 & $30 \%$ \\
\hline & Falta de tempo & 0 & 0 \\
\hline & Medo da injeção intramuscular & 9 & $45 \%$ \\
\hline & Medo dos efeitos colaterais & 1 & $5 \%$ \\
\hline & $\begin{array}{l}\text { Não possuir os documentos } \\
\text { necessários }\end{array}$ & 0 & 0 \\
\hline & $\begin{array}{l}\text { Não ser informado das } \\
\text { campanhas }\end{array}$ & 1 & $5 \%$ \\
\hline & Falta de interesse & 11 & $55 \%$ \\
\hline & $\begin{array}{l}\text { Dificuldade de locomoção até a } \\
\text { unidade de saúde }\end{array}$ & 0 & 0 \\
\hline & $\begin{array}{l}\text { Contraindicação por certos } \\
\text { agravos de saúde }\end{array}$ & 0 & 0 \\
\hline & $\begin{array}{l}\text { Outros (falta de interesse dos } \\
\text { responsáveis) }\end{array}$ & 2 & $10 \%$ \\
\hline \multirow{10}{*}{$\begin{array}{l}\text { Dentre os possíveis motivos que levam os adultos a } \\
\text { não se vacinarem, quais destes você considera mais } \\
\text { importante? }\end{array}$} & $\begin{array}{l}\text { Falta de conhecimento acerca da } \\
\text { importância da vacinação }\end{array}$ & 10 & $50 \%$ \\
\hline & $\begin{array}{c}\text { Falta de conhecimento sobre } \\
\text { onde e quando se vacinar }\end{array}$ & 0 & 0 \\
\hline & $\begin{array}{c}\text { Falta de conhecimento sobre } \\
\text { quais vacinas recomendadas para } \\
\text { sua idade }\end{array}$ & 6 & $30 \%$ \\
\hline & Falta de tempo & 8 & $40 \%$ \\
\hline & Medo da injeção intramuscular & 4 & $20 \%$ \\
\hline & Medo dos efeitos colaterais & 1 & $5 \%$ \\
\hline & $\begin{array}{l}\text { Não possuir os documentos } \\
\text { necessários }\end{array}$ & 0 & 0 \\
\hline & $\begin{array}{l}\text { Não ser informado das } \\
\text { campanhas }\end{array}$ & 0 & 0 \\
\hline & Falta de interesse & 11 & $55 \%$ \\
\hline & Dificuldade de locomoção até a & 0 & 0 \\
\hline
\end{tabular}


Research, Society and Development, v. 10, n. 6, e28410615925, 2021

(CC BY 4.0) | ISSN 2525-3409 | DOI: http://dx.doi.org/10.33448/rsd-v10i6.15925

\begin{tabular}{|c|c|c|c|}
\hline \multicolumn{4}{|c|}{ unidade de saúde } \\
\hline & $\begin{array}{c}\text { Contraindicação por certos } \\
\text { agravos de saúde }\end{array}$ & 0 & 0 \\
\hline & $\begin{array}{l}\text { Outros (acesso à informações de } \\
\text { movimentos anti-vacina) }\end{array}$ & 1 & $5 \%$ \\
\hline \multirow{13}{*}{$\begin{array}{l}\text { Dentre os possíveis motivos que levam os } \\
\text { adolescentes a não se vacinarem, quais destes você } \\
\text { considera mais importante? }\end{array}$} & $\begin{array}{l}\text { Falta de conhecimento acerca da } \\
\text { importância da vacinação }\end{array}$ & 9 & $45 \%$ \\
\hline & $\begin{array}{c}\text { Falta de conhecimento sobre } \\
\text { onde e quando se vacinar }\end{array}$ & 3 & $15 \%$ \\
\hline & $\begin{array}{l}\text { Falta de conhecimento sobre } \\
\text { quais vacinas recomendadas para } \\
\text { sua idade } \\
\end{array}$ & 7 & $35 \%$ \\
\hline & Falta de tempo & 0 & 0 \\
\hline & Medo da injeção intramuscular & 1 & $5 \%$ \\
\hline & Medo dos efeitos colaterais & 9 & $45 \%$ \\
\hline & $\begin{array}{c}\text { Não possuir os documentos } \\
\text { necessários }\end{array}$ & 0 & 0 \\
\hline & $\begin{array}{c}\text { Não ser informado das } \\
\text { campanhas }\end{array}$ & 1 & $5 \%$ \\
\hline & Falta de interesse & 2 & $10 \%$ \\
\hline & $\begin{array}{l}\text { Dificuldade de locomoção até a } \\
\text { unidade de saúde }\end{array}$ & 6 & $30 \%$ \\
\hline & $\begin{array}{c}\text { Contraindicação por certos } \\
\text { agravos de saúde }\end{array}$ & 1 & $5 \%$ \\
\hline & $\begin{array}{l}\text { Outros (acesso à informações de } \\
\text { movimentos anti-vacina) }\end{array}$ & 1 & $5 \%$ \\
\hline & Outros (falta de acompanhante) & 1 & $5 \%$ \\
\hline
\end{tabular}

Fonte: Autores.

O serviço de vacinação era disponível nos turnos da manhã e da tarde em todas as unidades, as quais exigiam o cartão SUS (100\%), carteira de vacinação (85\%) e CPF (25\%) como documentos necessários. Além disso, a maioria dos funcionários (55\%) acreditam que sua respectiva UBS atinge a meta recomendada pelo Ministério da Saúde e 60\% creem que as campanhas de imunização promovidas pela Secretaria de Saúde de Marabá são eficazes em conscientizar e atrair o público alvo em estudo.

Dentre os possíveis motivos que levam os adolescentes e adultos a não se vacinarem, os trabalhadores alegaram como principais: a falta de conhecimento acerca da importância da vacinação (70\% para adolescentes e 50\% para adultos) e a falta de interesse (55\% em ambos). Quando se trata dos idosos, destacam-se a falta de conhecimento acerca da importância da vacinação $(45 \%)$ e o medo dos efeitos colaterais $(45 \%)$. Os funcionários também foram questionados sobre o que poderia ser feito para aumentar a cobertura vacinal para adolescentes, adultos e idosos. As principais respostas foram agrupadas e organizadas na Figura 1. 
Figura 1: Estratégias para aumentar a cobertura vacinal para adolescentes, adultos e idosos, segundo os profissionais das salas de vacina de Marabá.

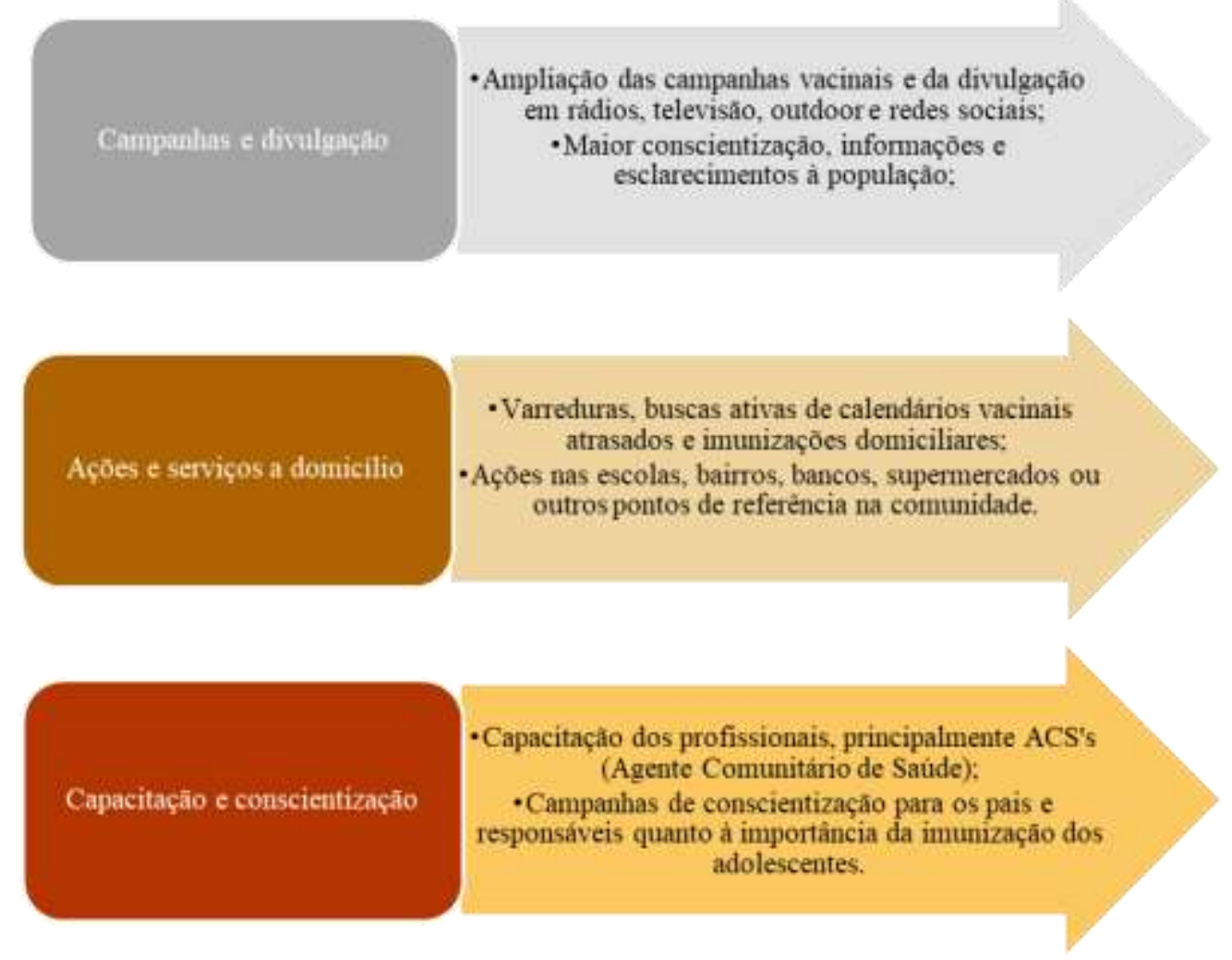

Fonte: Autores.

\section{Discussão}

O estudo apresentado evidenciou baixas coberturas vacinais em Marabá, de 2015 a 2019 (média de 57,49\%), cujos valores não atingem a meta preconizada pelo Mistério da Saúde, de 90\%. Nesse contexto, Oliveira et al. (2020) observaram que a região Norte possui a menor cobertura vacinal entre as cinco regiões do Brasil (79,2\%). O estado nortista com maior cobertura vacinal foi Rondônia $(100,02 \%)$ e com menor foi o Pará $(69,37 \%)$. A vacina BCG foi a única que apresentou cobertura vacinal média superior a $90(94,18 \%)$. Com isso, destaca-se que Marabá ainda possui uma cobertura menor que o estado onde encontra-se, o qual possui pior desempenho regional, conferindo preocupação e alerta para a situação.

Quando se discute sobre a vacinação de adolescentes, os resultados mostram que, em Marabá, de 2015 a 2020 , a cobertura vacinal de hepatite B, febre amarela e difteria e tétano (dT) não chegaram a 80\%: o melhor desempenho foi para febre amarela em $2019(79,72 \%)$ e o menor percentual foi para dT em 2015 (2,07\%). A cobertura para tríplice viral foi $108,08 \%$ em 2019 para a $1^{\text {a }}$ dose e $85,24 \%$ para a $2^{\text {a }}$ dose. Entretanto, esses dados não foram agrupados apenas na faixa etária adolescente, mas para todas as idades, sendo possível ter maior representatividade infantil nestes números.

Nesse sentido, Carvalho e Araújo (2010) entrevistaram 271 adolescentes residentes em áreas cobertas pela ESF e evidenciaram que a cobertura vacinal contra rubéola, sarampo e caxumba foi de 5,4\%; para a vacina contra difteria e tétano, foi de 22,9\%; para a vacina contra hepatite-B, foi $27,2 \%$ e 35,2\% para a vacina contra febre amarela. Já na pesquisa de Araújo et al. (2010), a vacina que apresentou maior cobertura foi a febre amarela (20\%), seguida da vacina tríplice viral (19\%) e da vacina contra Hepatite B (17\%). A vacina dT (contra difteria e tétano) apresentou uma cobertura extremamente baixa (2,5\%).

A menor cobertura para dT no presente estudo e no de Araújo et al. (2010) pode ser explicada pelo tempo 
relativamente longo para completar os seus esquemas vacinais, os quais apresentam um número de três doses com intervalos de um a seis meses entre elas.

Quanto à vacina contra HPV, Iwamoto et al. (2017) também observaram maior taxa de vacinação em mulheres em relação aos homens, o que pode ser explicado pela recente incorporação dos homens como público-alvo e pelo maior esforço na prevenção do câncer de colo do útero nas mulheres. Esquece-se, todavia, dos números alarmantes de câncer anorretal nos homens e o impacto físico, econômico e sociocultural das patologias provocadas pelo Papilomavírus humano.

É pertinente destacar que o amplo acesso às redes de comunicação e a disseminação em massa de informações, muitas vezes errôneas, aumentam a resistência relacionada à vacina. Ademais, a divulgação dos eventos adversos pós-vacinação na mídia muitas vezes dificulta a percepção da população acerca dos benefícios da vacinação (Iwamoto et al., 2017).

Ainda em relação aos adolescentes, os profissionais das salas de vacina elencaram, como os principais motivos que levam os jovens a não se vacinaram, a falta de conhecimento sobre a importância da vacinação (70\%) e a falta de interesse (55\%). Nessa perspectiva, Carvalho e Araújo (2010) verificaram que 36,8\% dos adolescentes entrevistados possuíam medo da dor ou temor à agulha, o que poderia ser um fator associado à falta de imunização. Neste mesmo estudo, 60,2\% dos jovens desconheciam o calendário vacinal para sua idade (versus 48,3\% no estudo de Araújo et al., em 2010), somente um terço conhecia a vacina contra febre amarela; e, menos de $20 \%$ a vacina contra hepatite-B e 18,7\% conheciam a vacina dT, o que ratifica a falta de conhecimento dos jovens ou até mesmo a falta de interesse por este assunto, como foi sugerido pelos funcionários marabaenses.

Além disso, ressalta-se que quase a totalidade dos adolescentes entrevistados nas duas pesquisas comparativas residiam em áreas cobertas pela ESF (Estratégia Saúde da Família). Em relação à isto, Carvalho e Araújo (2010) observaram que 92,7\% dos jovens procuraram o serviço de saúde e, destes, 97 (40,1\%) receberam informação sobre vacina, e 145 (59,9\%) não foram informados. Na comunidade, observou-se uma melhora do acesso à informação, com $57,1 \%$ dos entrevistados declarando que foram orientados quanto à vacinação, dentre estes, 48,3\% receberam informação na escola e 43,0\% em casa, quem mais informou foi o ACS (46,1\%). Esses resultados sustentam a necessidade de ampliação das campanhas e divulgação de informações, assim como a capacitação de ACS's e ações nas escolas, conforme o sugerido pelos profissionais das salas de vacina.

É importante frisar que as áreas cobertas pela ESF são alvos de estratégias de promoção à saúde, sendo também locais propícios à incorporação da proposta de saúde integral de adolescentes e jovens. O trabalho dos ACS oferece uma grande contribuição às ações de vacinação, porém, assim como os demais profissionais da atenção básica, ainda precisa ser mais atuante acerca da imunização. O adolescente que vai ao posto de saúde, deve ser interrogado sobre sua condição vacinal, além de ser imprescindível a observação do cartão por todos os profissionais de saúde. Estes devem agir no sentido de esclarecer aos jovens sobre a importância da imunização e do cartão de vacina (Araújo et al., 2010).

Quanto aos adultos, a falta de conhecimento acerca da importância da vacinação e a falta de interesse foram os principais motivos da não imunização selecionados pelos profissionais entrevistados. Em concordância, um estudo em Caxias (MA), com 62 adultos, identificou a desinformação (33,9\%), falta de interesse $(27,4 \%)$ e falta de tempo $(22,6 \%)$ como principais motivos que desfavorecem a adesão à vacinação. Na mesma pesquisa, $76 \%$ dos entrevistados desconheciam o calendário vacinal adulto e o percentual de imunização na amostra estudada foi: 56,6\% para dT, 37,1\% para febre amarela, 40,3 para hepatite B e 38,7\% para tríplice viral (Chaves \& Ross, 2014).

Em relação aos idosos, Santos et al. (2009) evidenciaram que, dos 509 idosos entrevistados, 76,4\% já haviam tomado a vacina anti-influenza, 73,9\% e 6,7\% já eram imunizados com a dT e pneumocócica 23. Contudo, na presente pesquisa, constata-se que o DATASUS não apresenta dados confiáveis sobre doses de vacina contra influenza aplicadas no município de Marabá, tampouco a cobertura vacinal deste imuno por faixa etária. 
Quanto aos principais motivos que levam os idosos a não se vacinarem, os profissionais citaram a falta de conhecimentos sobre a importância da imunização (45\%) e o medo dos efeitos colaterais (45\%). Concordantemente, Francisco et al. (2006) observaram que os motivos relatados pelos idosos que não se vacinaram foram: não considerar a vacina importante $(41,4 \%)$, crença de que a vacina provoca reação $(18,5 \%)$, ter adoecido após tomar a vacina em período anterior $(5,6 \%)$ e outros motivos $(32,6 \%)$. Assim, destaca-se a necessidade de não só informar sobre a importância da vacinação, como também conversar, entender os medos e crenças dos idosos e leva-los à reflexão acerca dos riscos e benefícios da imunização.

A problemática em torno da queda na taxa das imunizações, mostra que é necessário planejamento estratégico de acordo com as características de cada localidade, bem como direcionamento dos serviços de saúde, para acolher as demandas da população e evitar oportunidades perdidas de vacinação.

\section{Conclusão}

Mesmo com o desenvolvimento do PNI e a erradicação de várias doenças imunopreviníveis que pairavam sob o território brasileiro, os esforços para manter a população longe de ameaças epidemiológicas ainda necessitam ser fortalecidos. Surtos, epidemias e, até mesmo, pandemias ainda estão presentes. A recente reintrodução do Sarampo, por exemplo, evidenciou a indigência das baixas coberturas vacinais. A atual pandemia pela Covid-19 colocou o mundo atrás da esperança de uma vacina eficaz. A necessidade de informar, convencer e esclarecer a população sobre o impacto positivo e importância da imunização tornou-se prioridade.

Neste contexto, o presente estudo chama a atenção à ausência de vários dados no DATASUS, assim como a baixa cobertura vacinal no município de Marabá/PA, de 2015 a 2020 (57,49\%). Para adolescentes, adultos e idosos, a cobertura de todas as vacinas precisa ser ampliada. Da mesma forma, este público deve ser atraído e conscientizado, já que diversos estudos ratificaram a falta de conhecimento e interesse da população em questão. Ademais, medos e crenças dos idosos devem ser trabalhados a fim de fazê-los refletir sobre os riscos e benefícios da vacinação.

Por fim, as estratégias de aumento da cobertura vacinal apresentadas pelos profissionais das salas de vacina do município são extremamente válidas: capacitação de ACS's, melhor divulgação em rádios, televisões, outdoor e redes sociais, palestras e ações em escolas, supermercados e outros pontos de referência na comunidade e, não menos importante, varreduras, buscas ativas de calendários vacinais atrasados e imunizações domiciliares. E, dessa forma, em meio a uma pandemia que vitimiza milhares de pessoas no mundo todos os dias, nunca foi tão necessário discutir, avaliar e ampliar a imunização. Faz-se necessário estudos para os anos seguintes, para ver a evolução da cobertura vacinal no município.

\section{Referências}

Araújo, T. M. E. de., Sá, L. C. de., Silva, A. A. de S., \& Costa, J. P. (2010). Cobertura vacinal e fatores relacionados à vacinação dos adolescentes residentes na área norte de Teresina/PI. Revista Eletrônica De Enfermagem, 12 (3): 502-510.

Arroyo, L. H. (2020]0. Áreas com queda da cobertura vacinal para BCG, poliomielite e tríplice viral no Brasil (2006-2016): mapas da heterogeneidade regional. Cadernos de Saúde Pública, 36 (4): e00015619.

Baptista, D.M.T. (1999). O debate sobre o uso de técnicas qualitativas e quantitativas de pesquisa. In: Martinelli, M. L. (Org.) Pesquisa qualitativa: um instigante desafio: Veras Editora.

Carvalho, A. M. C., \& Araújo, T. M. E. (2010). Fatores associados à cobertura vacinal em adolescentes. Acta Paulista de Enfermagem, 23 (6): $796-802$.

Chaves, L. H. S., \& Ross, J. R. (2014). Profile of the adults registered in a microarea of the Family HealthmStrategy. Revista de Enfermagem da UFPI, 3 (4):4-9.

Domingues, C. M. A. S., Fantinato, F. F. S. T., Duarte, E., \& Garcia, L. P. (2019). Vacina Brasil e estratégias de formação e desenvolvimento em imunizações. Epidemiologia e Serviços de Saúde, 28 (2): e20190223.

Ferreira, V. L. R., Waldman, E. A., Rodrigues, L. C., Martineli, E., Costa, A. A., Inenami, M., \& Sato, A. P. S. (2018). Avaliação de coberturas vacinais de crianças em uma cidade de médio porte (Brasil) utilizando registro informatizado de imunização. Cadernos de Saúde Pública, 34 (9): e00184317. 
Research, Society and Development, v. 10, n. 6, e28410615925, 2021

(CC BY 4.0) | ISSN 2525-3409 | DOI: http://dx.doi.org/10.33448/rsd-v10i6.15925

Oliveira, G. S., Bitencourt, E. L., Amaral, P. F. F., Reis Junior, P. M., Vaz, G. P., \& Costa, S. B. (2020). Cobertura vacinal: uma análise comparativa entre os estados da região Norte do Brasil. Revista de Patologia do Tocantins. 7 (1): 14-17.

Marabá (2016). Secretaria Municipal de Saúde. Coordenação da Estratégia de Saúde da Família.

Ministério da Saúde. Secretaria de Atenção à Saúde. Área de Saúde do Adolescente e do Jovem. Marco legal: saúde, um direito de adolescentes: Ministério da Saúde.

Ministério da Saúde. Manual do Usuário, Sistema de Informações do Programa Nacional de Imunizações/Avaliação do Programa de Imunizações: Ministério da Saúde.

Ministério da Saúde. Secretaria de Vigilância em Saúde. Programa Nacional de Imunizações: Ministério da Saúde.

Ministério da Saúde. Sarampo: situação epidemiológica: Ministério da Saúde.

Moraes, J. C., Luna, E. A., \& Barbosa, H. (2007). Inquérito de cobertura vacinal nas áreas urbanas das capitais: Centro de Estudos Augusto Leopoldo Ayrosa Galvão.

Porto, A., \& Ponte, C. F. (2003). Vacinas e campanhas: imagens de uma história a ser contada. História, Ciências, Saúde. Manguinhos, vol. 10 (2): $725-42$.

Marabá. (2021). Prefeitura de Marabá. SMS: Comunidade dos Bairros Araguaia e Nossa Senhora Aparecida recebem Unidade Básica de Saúde. < https://maraba.pa.gov.br/sms-comunidade-dos-bairros-araguaia-e-nossa-senhora-aparecida-recebem-unidade-basica-de-saude/>.

Medeiros, E. A. S. (2020). Entendendo o ressurgimento e o controle do sarampo no Brasil. Acta Paulista de Enfermagem, 33: e-EDT20200001.

Organização Pan-americana da Saúde (OPAS). (2021). Organização Mundial da $\quad$ Saúde. Sarampo. Brasília: OPAS. <https://www.paho.org/pt/topicos/sarampo>.

Santos, B. R. L., Creutzberg, M., Cardoso, R. F. M. L., Lima, S. F., Gustavo, A. S., Viegas, K. W. M., \& Souza, A. C. A. (2009). Situação vacinal e associação com a qualidade de vida, a funcionalidade e a motivação para o autocuidado em idosos. Revista Brasileira de Epidemiologia. 12 (4): 533-540.

Sato, A. P. S. (2018). Qual a importância da hesitação vacinal na queda das coberturas vacinais no Brasil? Revista de Saúde Pública, 52 (96):1-9.

Sociedade Brasileira De Imunizações (SBIM). (2019). Imunização de adultos e idosos: bases para estudos e decisões: Magic RM. 